\title{
A MODEL OF FACTORS AFFECTING DOMESTIC TOURIST SATISFACTION ON ECO-TOURISM SERVICE QUALITY IN THE MEKONG DELTA, VIETNAM
}

\author{
Ha Nam Khanh GIAO \\ Faculty of Air Transport, Vietnam Aviation Academy, Ho Chi Minh City 700000, Vietnam, e-mail: khanhgiaohn@yahoo.com \\ Bui Nhat VUONG* \\ Faculty of Air Transport, Vietnam Aviation Academy, Ho Chi Minh City 700000, Vietnam, e-mail: nhatvuonga1@ gmail.com \\ Nguyen Ngoc Duy PHUONG \\ International University - Vietnam National University, Ho Chi Minh City 700000, Vietnam, e-mail: nndphuong@hcmiu.edu.vn
}

Ngo Tan DAT

Faculty of Air Transport, Vietnam Aviation Academy, Ho Chi Minh City 700000, Vietnam, e-mail: tandat.hospitality@gmail.com

\begin{abstract}
Citation: Giao, H.N.K., Vuong, B.N., Phuong, N.N.D., \& DAT, N.T. (2021). A MODEL OF FACTORS AFFECTING DOMESTIC TOURIST SATISFACTION ON ECO-TOURISM SERVICE QUALITY IN THE MEKONG DELTA, VIETNAM. GeoJournal of Tourism and Geosites, 36(2spl), 663-671. https://doi.org/10.30892/gtg.362spl14-696
\end{abstract}

\begin{abstract}
The objective of the present study is to explore the factors affecting domestic tourists' satisfaction with the quality of ecotourism services. Survey data collected from 457 visitors visiting Mekong Delta, Vietnam were analyzed to provide evidence. Results from multiple regression analysis using SPSS software have determined that Food and beverage Shopping \& entertainment services, Perceived price, Nature destination landscape, Security and Safety, Transportation had positive associations with domestic travelers' satisfaction. Besides, this research also showed that female tourists tend to be more satisfied than male tourists. The main findings of this study provide practical implications for travel agencies and tourism managers. It implies that they should improve these factors in order to maintain and enhance domestic tourist satisfaction with the quality of ecotourism services in Mekong Delta, Vietnam.
\end{abstract}

Key words: tourist satisfaction, service quality, Mekong Delta, ecotourism

$* * * * * *$

\section{INTRODUCTION}

Tourism is one of the fastest-growing industries in the world and it plays an important role in the economy and stimulates the growth of other economies as well (Osman and Sentosa, 2013). Dubbed the "smokeless industry", the tourism industry outperformed the global economy in 2019 and the development is faster than manufacturing, retail, financial services, and media. Tourism brings many other benefits to both economy and society such as the increase of revenue, creating many job opportunities, the strong attracting of investment resources, especially strategic investors to major areas of Vietnam tourism. Besides, the tourism industry also contributes to restoring, preserving, and promoting the value of heritage, tangible and intangible relics in localities. The development of tourism significantly contributes to poverty reduction and economic restructuring. When the people's life is better, the demand for tourism also becomes popular. Indeed, there are many profits from traveling like releasing stress, experiencing new things, and improving the knowledge of culture, traditions, and cuisine in unfamiliar lands (Goliath-Ludic and Yekela, 2020).

And once the human demand increases, the quality of tourism services is also stricter. Thus, the managers do not focus on the service quality, tourists feel dissatisfied and give up the destination in turn. On the contrary, if managers grasp and respond to these needs, this will be one of the reasons why they are willing to return. The significant contribution to the development of Vietnam's tourism is the participation of many Southern provinces and cities. Toward Tourism in Southwest Vietnam, especially the type of Ecotourism with mangrove ecosystems, melaleuca forests, island systems, bird sanctuaries, traditional festivals have created a unique color for Ecotourism in the South West, Vietnam. In order to improve the level of domestic customer satisfaction for tourism development in the province, the objective of this study is to examine factors affecting domestic tourist satisfaction on the quality of tourism services in the Mekong Delta Vietnam.

\section{LITERATURE REVIEW}

\section{Tourism, Traveler and Eco-Tourism}

According to Hunter and Green (1995), tourism is a leisure activity in people's free time related to traveling and staying in places outside their usual environment for leisure, healthcare, physical and mental development, knowledge improvement purposes, along with the consumption of natural, economic and cultural values. According to Setokoe (2020), tourism comprises activities related to people traveling to places outside their usual environment for visiting, learning, relaxing, and

\footnotetext{
* Corresponding author
} 
leisure purposes within a particular period of time. Giao et al. (2020) define a visitor as a traveler taking a trip to the main destination outside his/her usual environment, for more than 24 hours and less than a year for business, leisure, or other personal purposes other than to be employed by a resident entity in the country or place visited.

Based on Patwary et al. (2021), a visitor is a person traveling or combining tourism purposes on a trip, except for income-generating purposes at the destination. Thus, a tourist is a person who travels and stays outside of his / her regular residence to visit, learn, entertainment or relaxation for a certain period of time. In relation to Stonehouse (1999), ecotourism is an activity in which people travel to natural areas which are less polluted and not used for any special purposes including research, appreciation of nature, and wild flora and fauna (both in the past and the present) explored in these areas. Besides, Wood (2002) considers ecotourism as an activity in which people travel to pristine areas to learn about the history of the natural environment and the culture without affecting ecosystems, and generates economic opportunities to preserve the environment and bring financial benefits to local residents.

\section{Service Quality}

A service is an activity or a chain of activities that take place when there is an interaction between two parties, a consumer and a service provider (Gronroos, 1990). Zeithaml and Bitner (2018) consider service as an activity, a process, and a way to perform a job to create value for customer satisfaction in the present time. Kotler and Keller (2012) define a service: A service is an activity or benefit provided for exchange that is primarily intangible and does not result in a tran sfer of ownership. The performance of service may or may not be associated with a physical product.

Gronroos (1990) said that service quality is measured by comparing the value that customers expect before using the service and the value that customers receive when using the service. Parasuraman et al. (1988) show that service quality is the level of difference between the consumer's expectation of service and their perception of the result of the service. In other words, service quality is the difference between the quality expected by the customer and the quality they perceive to be actually delivered. According to Chuchu (2020), the quality of tourism service is the suitability level of services by tourism suppliers that satisfy the needs of tourists in the target market.

\section{Customer satisfaction}

There are many studies on customer satisfaction, under which authors also have many different definitions of customer satisfaction. According to Oliver (2010), satisfaction is a result of the comparison between the pre-use expectation and their feeling after the customer has used the product. In relation to Zeithaml and Bitner (2018), customer satisfaction is the key to the success of a business and is the basis for evaluating the quality of services that businesses have provided to customers. Meeting and satisfying customers' needs are considered the most useful strategy to attract and retain customers in the current period.According to Pizam et al. (1978), customer satisfaction is a result of the interaction of real experience and the expectation about the destination of customers. Likewise, Oliver (2010) believes the disparity between customer expectations and their real experience that tourism products affect their emotions will determine the level of satisfaction with those products.

\section{The relationship between service quality and customer satisfaction}

Over the past decades, many studies on customer satisfaction have been performed. Besides, the topic of the relationship between service quality and customer satisfaction has also been discussed continuously. In general, research all concludes that service quality and satisfaction are two separate concepts but have a close relationship as customer satisfaction is seen as a result, service quality is seen as a reason; satisfaction is predictable, and service quality is an ideal benchmark. According to Zeithaml and Bitner (2018), customer satisfaction is affected by many factors including products, service quality, prices, situational factors, and personal factors.

Oliver (2010) considers that service quality affects customer satisfaction levels. The more the service provided meets customer expectations, the more satisfied customers will become. According to Parasuraman et al. (1988), service quality is determined by many constituent factors and is the main determinant of customer satisfaction. Service quality is the factor affecting customer satisfaction the most (Cronin and Taylor, 1992). If a service provider gives customers quality products that satisfy their needs, that business will initially make customers satisfied. Research by Spreng and Mackoy (1996) also states that service quality is the premise of customer satisfaction. Therefore, in order to improve customer satisfaction, service providers must improve service quality. In other words, service quality and customer satisfaction are closely related. Service quality is first achieved before determining customer satisfaction.

\section{HYPOTHESIS DEVELOPMENT}

This study selected a model based on the service quality measurement model of Gronroos (1990), Parasuraman et al. (1988), and the model to measure satisfaction by Zeithaml and Bitner (2018). These are selected models studied in many fields in many Asian countries, including some tourism researches. In addition, research-based on empirical studies on satisfaction with service quality has been carried out by some researchers, including Narayan et al. (2008), Hau and Omar (2014) to study customer satisfaction with tourism service quality. This will be a solid theoretical basis to help research and apply the model suitable to the research conditions in Vietnam's Mekong Delta.Based on qualitative research findings, 2/3 of the members have agreed with 06 factors affecting the level of satisfaction with the quality of tourism services: (1) Tourism infrastructure, (2) Nature destination landscape, (3) Transportation, (4) Food and beverages, Shopping and entertainment services, (5) Security and safety, (6) Tour guide. Also, the group added another factor that was assessed as having a significant influence on the satisfaction of tourism service quality, (7) Perceived Price, to the study in the Mekong Delta, Vietnam (Figure 1). 


\section{Tourism Infrastructure}

Tourism infrastructure is an important factor affecting the satisfaction of tourists because of its capacity and utility. Man uses technical facilities to exploit the value of tourism resources to create services and goods for tourists. In addition to resources, the diversity, abundance, modernity, and attractiveness of the facilities and techniques also create the diversity, abundance, and attractiveness of tourism services. The infrastructure comprises all of the existing physical foundations in tourist attractions on which tourism service operators can conduct business, providing services for the enjoyment of tourists: restaurants, hotels, motels, tourist attractions, ease of travel, access to attractions. The research conducted by Foroni et al. (2019) pointed out the relationship between tourism infrastructure and tourist satisfaction. The above arguments lead to hypothesis $\mathrm{H}_{1}$ :

$H_{1}$ : Tourism infrastructure correlates to domestic tourists' satisfaction with the quality of ecotourism services in Vietnam's Mekong Delta.

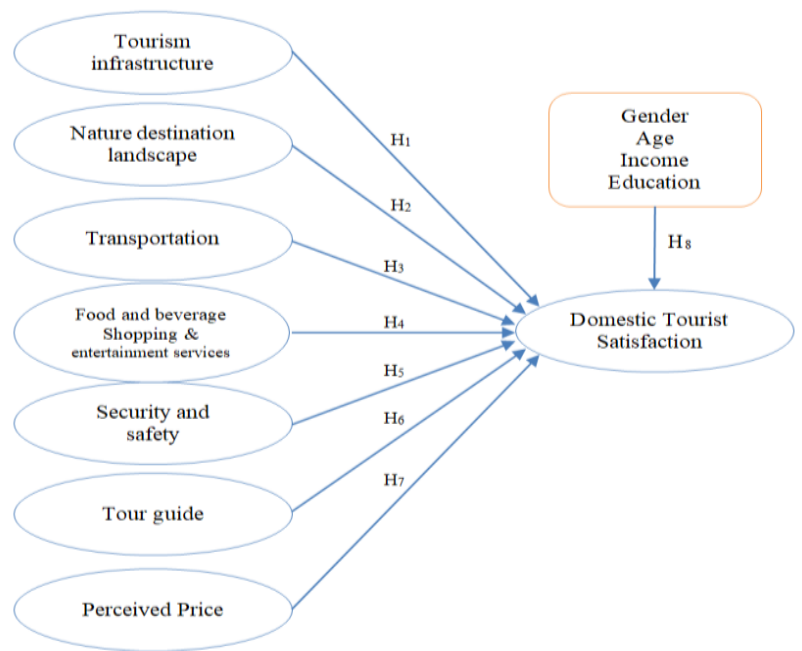

Table 1. The Tourist Characteristics

\begin{tabular}{|c|c|c|c|}
\hline & & Frequency & Percentage (\%) \\
\hline \multirow{3}{*}{ Gender } & Female & 163 & 35.7 \\
\cline { 2 - 4 } & Male & 294 & 64.3 \\
\hline \multirow{4}{*}{ Age } & $18-25$ years old & 93 & 20.4 \\
\cline { 2 - 4 } & $26-35$ years old & 274 & 60.0 \\
\cline { 2 - 4 } & $36-45$ years old & 60 & 13.1 \\
\cline { 2 - 4 } & $>45$ years old & 30 & 6.6 \\
\hline \multirow{4}{*}{ Income } & $<5$ million & 141 & 30.9 \\
\cline { 2 - 4 } & $5-10$ million & 124 & 27.1 \\
\cline { 2 - 4 } & $10-15$ million & 152 & 33.3 \\
\cline { 2 - 4 } & $>15$ million & 40 & 8.8 \\
\hline \multirow{3}{*}{ Education } & High School & 40 & 8.8 \\
\cline { 2 - 4 } & College & 60 & 13.1 \\
\cline { 2 - 4 } & Bachelor & 348 & 76.1 \\
\cline { 2 - 4 } & Postgraduate & 9 & 2.0 \\
\hline & Total & 457 & 100.0 \\
\hline
\end{tabular}

Figure 1. The research model (The model was proposed by the authors)

\section{Nature destination Landscape}

Nature destination landscape is a basic element of a tourist destination, drawing the interest of tourists and tourism managers. People are always excited about the beautiful natural scenery or the cool, fresh climate. Tourism is an opportunity for visitors to admire and experience magnificent things with their naked eyes or learn lessons from nature, history, and culture that people have created. The better impression that the tourism landscape gives visitors, the more satisfied they will become. Therefore, finding, exploiting, maintaining, and conserving natural resources and unique cultural features of the local people is of immense importance. Therefore, it can be said that the tourism scene is an important tourism engine, affecting tourist satisfaction. Research by Jiménez-García et al. (2020) has shown a positive relationship between the tourism landscape and tourist satisfaction. The above arguments lead to hypothesis $\mathrm{H}_{2}$ :

$\mathrm{H}_{2}$ : Nature destination landscape correlates to domestic tourists' satisfaction with the quality of ecotourism services in the Mekong Delta, Vietnam.

\section{Transportation}

Transportation is instrumental in facilitating visitors to easily follow the route combining sightseeing destinations, safe, fast, and shorten journey times. Waterway transport can be combined with sightseeing tours along the river with the system of facilities for modern comfortable trips. Convenient means of transportation for tourists is a condition that influences the choice of destination for tourists and contributes to their satisfaction. Kanwal et al. (2020) confirmed that a positive relationship between Transportation and tourist satisfaction. The above arguments lead to hypothesis $\mathrm{H}_{3}$ :

\section{$H_{3}$ : Transportation correlates to tourists' satisfaction with the quality of ecotourism services in the Mekong Delta, Vietnam.}

\section{Food and beverage, shopping, and entertainment services}

Food and beverage services, shopping, and entertainment services have an impact on the quality of tourism services. It is imperative to serve visitors at restaurants, hotels, and other food and beverage establishments with diverse regional foods, traditional features, types, good hygiene, food safety, attentive and polite service style with a network of professional stores to meet diverse and diverse needs, from food and vegetable stores, souvenir shops to specialized tourism shops, consumer goods stores. Sports facilities include sports facilities, sports halls or sports centers of various types, specialized equipment for each type. Cultural centers include cinemas, theaters, tribal trees, galleries. The study of Narayan et al. (2008) pointed out a positive relationship between food service, shopping and entertainment, and tourist satisfaction. The above arguments lead to hypothesis $\mathrm{H}_{4}$ :

$H_{4}$ : The quality of food and beverage services, shopping and entertainment services correlates to domestic tourists' satisfaction with the quality of ecotourism services in the Mekong Delta, Vietnam. 


\section{Security and Safety}

Security has an increasingly stronger impact on the quality of tourism services when courtesy, politeness, as well as security maintenance, safety, and hygiene are required to develop tourism, while acts of robbery, hacking, forcing tourists should be eliminated. The study of Narayan et al. (2008) showed a correlation between security and safety and the satisfaction of tourists. The above arguments lead to hypothesis $\mathrm{H}_{5}$ :

$\mathrm{H}_{5}$ : Security and safety correlate with domestic tourists' satisfaction with the quality of ecotourism services in the Mekong Delta, Vietnam.

\section{Tour Guide}

Tour guides and staff at tourist sites interact directly with tourists. Any tourist who comes to a new place wants to be warmly welcomed and well-treated by the tour staff and residents of this place. Therefore, we can say a tour guide is an important factor affecting the satisfaction of visitors when they come to a tourist destination. The willingness of tour guides, staff, and managers at tourist sites to give help and guidance when welcoming tourists to visit and during the tour of tourists is as well as their enthusiastic and cheerful service will make tourists feel happier and more satisfied with their experience. The above arguments lead to hypothesis $\mathrm{H}_{6}$ :

$H_{6}:$ Tour guides correlate to domestic tourists' satisfaction with the quality of ecotourism services in the South West, Vietnam.

\section{Perceived Price}

Price is the amount of money spent by tourists to enjoy products and services at the tourist destination, including the tour price, accommodation, transport, local transport; and prices of food in restaurants, resorts, shopping prices. Narayan et al. (2008) demonstrated that a correlation between price perceived and traveler satisfaction. From the above arguments, we have a hypothesis $\mathrm{H}_{7}$ :

\section{$H_{7}:$ Perceived price correlates to domestic tourists' satisfaction with the quality of ecotourism services in the South West,} Vietnam.

\section{Control variables}

Demographic variables, such as age, gender, income, and educational background, are called customer characteristics. To a certain extent, these characteristics are a significant determinant of consumer behavior (Kwok et al., 2016). Therefore, the author proposes hypothesis $\mathrm{H}_{8}$ as follows:

$H_{8}:$ There is a difference in domestic tourists' satisfaction with the quality of ecotourism services in the Mekong Delta, Vietnam, depending on individual characteristics.

\section{RESULT}

\section{Overview of ecotourism in the Southwest, Viet Nam}

According to Southwest Region Information Tourism and Promotion Center, Viet Nam, there were over 1.2 million tourists visiting the Southwest region of Vietnam in 2019; including more than 1.15 million domestic tourists. Compared to 2018, the number of visitors in 2019 increased by 21.7. The area of Viet Nam's Southwest is 5,294 square kilometers. It has two mangrove and wetland ecosystems in South West Cape National Park, Vietnam, and U Minh Ha National Park, which is belonging to the South West Cape World Biosphere Reserve, Vietnam. Based on the advantage of nature, the province developed ecotourism products. Besides that, the province also organizes humanistic tourism potentials such as the Nghinh Ong Song Doc festival, jokes by folk artist Nguyen Long Phi (Ba Phi), many cultural and historical relics that may be unique elements of sightseeing programs of the province. The Southwest of Viet Nam has many tourist attractions such as: Ca Mau National Park, Khai Long tourist area, Ong Trang islet, Forest fishing ground 184, Hon Khoai Island cluster, historic site - Silver stone scenic spots, bird sanctuary city Southwestern, Vietnam, ecological conservation area of forest and fishery of Trem River, U Minh Ha National Park. Moreover, U Minh Ha National Park has attracted many foreign tourists and scientists to research. U Minh Ha has a rich biological resource with 12 amphibian species, 32 reptile species, 100 bird species, 18 mammal species (Vietnamplus, 2019). The tourism activities that occur here have to follow a range of criteria such as ensuring conservation and history, using tourism resources appropriately, maintaining essential ecosystems of forests, ensuring a stable life for local communities. With a diverse ecosystem and the Southern point of the country, the Southwest region of Vietnam has many advantages in tourism development. However, Southwest Viet Nam is speeding up toward the socialization of tourism to effectively exploit available resources.

The big turning point of tourism in the Southwest, Vietnam is that the Ho Chi Minh route from Nam Can to Dat Mui has been through technical traffic, officially connecting Ho Chi Minh road from the starting point at Pac Bo (Cao Bang) to the endpoint at Dat Mui (South West), Vietnam. Therefore, visitors are able to reach the southernmost point of the country by road, saving time and creating more transportation options rather than waterways. In the southwestern region, Vietnam has always identified tourism as a crucial economic sector, so tourism development does not focus too much on immediate profits but ensures how to get long-term profits. In the master plan on tourism development in the southwestern region, Vietnam to 2025 and orientations to 2030, the province has identified the viewpoint as "Tourism development is associated with sustainable socio-economic development, national defense, social order and safety, preservation and promotion of cultural values of the nation" (Chinhphu, 2020). 


\section{Descriptive statistics}

The study was conducted in the southwestern province of Vietnam, and the survey subjects were domestic tourists visiting and staying here. Total 462 questionnaires were responded to by tourists in the South West, Vietnam in 2019. However, there are 457 valid samples (response rate $98.92 \%$ ) that meet the criteria used for the study. The questionnaire was coded and data processed using SPSS 20 software for analysis (Table 1). The results show that there is a remarkable difference in terms of gender in the sample size and the majority of survey tourists are male. The surveyed participants are from 26 to 35 years old, and the income from 10 to 15 million accounts for a high percentage. Besides, visitors participating in the survey with university degrees accounted for $76.1 \%$.

\section{The assessment of Reliability and Validity}

The scale was first to be analyzed for Cronbach's Alpha reliability coefficient, variables with an item-total correlation less than 0.3 will be rejected and the scale will be accepted for analysis in the following steps when Cronbach Alpha's reliability is from 0.7 and above (Giao et al., 2020). After testing Cronbach's Alpha two times, there are 4 observed variables CSHT2, CSHT4, HDDL1, HDDL4 that were eliminated due to Cronbach's Alpha coefficient $<0.7$. Besides, in the first discovery factor analysis, the variable PCDL3 $<0.5$ was also eliminated. The figure shows that the Cronbach's Alpha coefficient of the scale fluctuates in the range from 0.820 to 0.930 and the smallest correlation coefficient of the observed variables of the scale is 0.515. Overview, Cronbach's Alpha coefficients of the scales were quite high (>0.7) and all observed variables of this scale had a total variable correlation coefficient greater than 0.3 , thus they achieved very good reliability. In addition, Vuong and Suntrayuth (2020) have proposed to use the coefficients of the discovery factor to measure the value of scales of the study. Factor load factor should be greater than 0.5 and it is considered to be of practical significance. As shown in Table 2 , most values of the load factor for each index are higher than 0.5 (minimum value 0.625 ). Consequently, each structure exhibits a good convergence value. From the results above, we can conclude that the scales applied in the research model are achieving very good reliability and validity. Therefore, these scales will be used for analysis in multiple regression models.

Table 2. Reliability and Validity

\begin{tabular}{|c|c|c|c|c|c|c|c|c|c|c|c|}
\hline \multirow{2}{*}{ Scale } & \multirow{2}{*}{$\begin{array}{l}\text { Observed } \\
\text { Variables }\end{array}$} & \multirow{2}{*}{\begin{tabular}{|c|}
$\begin{array}{c}\text { Validity } \\
\text { calculation }\end{array}$ \\
$\begin{array}{c}\text { Factor } \\
\text { Loading }\end{array}$ \\
\end{tabular}} & \multicolumn{2}{|r|}{ Reliability } & \multicolumn{7}{|c|}{ Matrix Correlation } \\
\hline & & & $\begin{array}{c}\text { Cronbach's } \\
\text { alpha }\end{array}$ & $\begin{array}{c}\text { Minimum variable-total } \\
\text { correlation coefficient }\end{array}$ & CSHT & PCDL & PTVC & DVAU & ANTT & HDDL & $\mathrm{GCCN}$ \\
\hline \multirow{3}{*}{$\begin{array}{c}\text { Tourism } \\
\text { Infrastructure }\end{array}$} & CSHT3 & 0,902 & \multirow{3}{*}{0,903} & \multirow{3}{*}{0,775} & \multirow{3}{*}{1} & & & & & & \\
\hline & CSHT1 & 0,901 & & & & & & & & & \\
\hline & CSHT5 & 0,890 & & & & & & & & & \\
\hline \multirow{3}{*}{$\begin{array}{l}\text { Tourism } \\
\text { Landscape }\end{array}$} & PCDL1 & 0,754 & \multirow{3}{*}{0,737} & \multirow{3}{*}{0,539} & \multirow{3}{*}{$-0,597^{* *}$} & \multirow{3}{*}{1} & & & & & \\
\hline & PCDL2 & 0,692 & & & & & & & & & \\
\hline & PCDL4 & 0,664 & & & & & & & & & \\
\hline \multirow{5}{*}{ Transport } & PTVC2 & 0,840 & \multirow{5}{*}{0,820} & \multirow{5}{*}{0,515} & \multirow{5}{*}{$-0,292^{* *}$} & \multirow{5}{*}{$0,456^{* *}$} & \multirow{5}{*}{1} & & & & \\
\hline & PTVC4 & 0,823 & & & & & & & & & \\
\hline & PTVC3 & 0,774 & & & & & & & & & \\
\hline & PTVC1 & 0,687 & & & & & & & & & \\
\hline & PTVC5 & 0,625 & & & & & & & & & \\
\hline \multirow{5}{*}{\begin{tabular}{|c|} 
Food and \\
Beverage \& \\
Shopping \\
Entertainment \\
Service \\
\end{tabular}} & DVAU3 & 0,801 & \multirow{5}{*}{0,858} & \multirow{5}{*}{0,639} & \multirow{5}{*}{$-0,485^{* * *}$} & \multirow{5}{*}{$0,527^{* *}$} & \multirow{5}{*}{$0,362^{* *}$} & & & & \\
\hline & DVAU1 & 0,777 & & & & & & & & & \\
\hline & DVAU2 & 0,743 & & & & & & 1 & & & \\
\hline & DVAU5 & 0,686 & & & & & & & & & \\
\hline & DVAU4 & 0,672 & & & & & & & & & \\
\hline & ANTT1 & 0,812 & & & & & & & & & \\
\hline & ANTT2 & 0,769 & & & & & & & & & \\
\hline Security \& & ANTT3 & 0,723 & 0,847 & 0,631 & $-0,598^{* *}$ & $0,549^{* *}$ & $0,386^{* *}$ & $0,597^{* *}$ & 1 & & \\
\hline & ANTT5 & 0,689 & & & & & & & & & \\
\hline & ANTT4 & 0,663 & & & & & & & & & \\
\hline & HDDL2 & 0,920 & & & & & & & & & \\
\hline & HDDL5 & 0,894 & & & $0661^{* * *}$ & $-0332^{* * *}$ & $-0106^{*}$ & & $-0.478^{* *}$ & & \\
\hline Tour Guide & HDDL3 & 0,842 & 0,920 & 0,801 & 0,661 & $-0,332$ & $-0,106$ & $-0,3 / 8$ & $-0,4 / 8$ & 1 & \\
\hline & QDDT3 & 0,799 & & & & & & & & & \\
\hline & GCCN3 & 0,861 & & & & & & & & & \\
\hline Perceived & GCCN1 & 0,770 & 0830 & 0598 & $-0287^{* * *}$ & $0.157^{* *}$ & $0150^{* * *}$ & $0399^{* * *}$ & $0508^{* *}$ & $-0284^{\text {*** }}$ & 1 \\
\hline Price & GCCN2 & 0,691 & 0,850 & 0,098 & $-0,28 /$ & $0,13 /$ & & & & $--1,204$ & 1 \\
\hline & GCCN4 & 0,653 & & & & & & & & & \\
\hline & SHL2 & 0,862 & & & & & & & & & \\
\hline Tourist's & SHL1 & 0,855 & 0.866 & & $0.429^{* * *}$ & $0,537^{* *}$ & $0,422^{* *}$ & $0,639^{* * *}$ & $0.607^{* *}$ & $0,288^{* * *}$ & $0,487^{*}$ \\
\hline satisfaction & SHL4 & 0,843 & 0,800 & 0,084 & & | ונכ, & 0,422 & 0,059 & & & \\
\hline & SHL3 & 0,821 & & & & & & & & & \\
\hline
\end{tabular}

\section{The Correlation Analysis and Regression}

Before the implementation of regression analysis, the author applied Pearson's correlation coefficient to quantify the rigor of the linear relationship between two independent and dependent variables (Vuong and Giao, 2020). In Pearson correlation 
analysis, there was no distinction between the independent and the dependent variables, all variables were considered equally. However, if the variables are strongly correlated, the multi-collinearity problem must be considered after regression analysis. The results of the correlation matrix (Table 2) show that the significance of most coefficients is very small $($ sig $=0<0.05)$, so most of the correlation coefficients are statistically significant and they were enough conditions for regression analysis.

On the basis of the scale of factors affecting visitor satisfaction, a linear correlation was considered, continuing to use regression analysis to see the relationship between these factors. The multicollinearity evaluation is the first step in a regression analysis. This procedure is necessary to ensure that the coefficients estimated by regressing the independent variables on the dependent variable are not biased. In regression, multicollinearity exists when two or more independent variables are highly correlated. The multicollinearity of the regression increases the standard error, making the important tests of the independent variables unreliable. High multicollinearity weakens a researcher's ability to make judgments about the relative importance of one variable independent of another (Giao et al., 2020). Therefore, when multicollinearity is high, the researcher must avoid a comparative analysis of the importance of the index based on path weights. According to (Giao et al., 2020), multicollinearity can occur if the magnified variance coefficient (VIF) exceeds 5. According to Table 3, the VIF coefficient reaches the maximum value of 2,631 (less than 5). These independent variables do not have a close relationship with each other, so there is no multicollinearity phenomenon occurring. The quality of the regression model should be assessed by the suitability index of the modified R2 model Vuong et al. (2020). These authors also proposed that the adjusted R2 coefficients are above 0.26, indicating that the quality of the model has a large influence; ranged from 0.13 to 0.26 for medium effect and less than 0.02 for a small effect. Based on figure 3, the result shows that the adjusted R2 value of model 1 is 0.657 , which means $65.7 \%$ of the variation. Domestic tourist satisfaction is explained by the variation of 05 independent variables such as tourist landscape, transports, Food and Beverage Service, Shopping and Entertainment Service, Security and Safety, Perceived Price.

Based on the results of multiple regression analysis (Table 3), the regression model shows that 05 independent variables GCCN, PTVC, PCDL, DVAU, ANTT have a positive impact on the dependent variable SHL because of the standardized regression coefficients. $(\beta)$ of these variables are positive and statistically significant (Sig. $<0.05$ ). Comparing the impact of these 5 variables on the dependent variable Domestic Visitor Satisfaction (SHL) in descending order as follows: we see that the variable Food service, shopping, and entertainment (DVAU) has the strongest impact $(\beta 4=0.314$ ), followed by perceptible price variable $(\mathrm{GCCN})(\beta 7=0.246)$, followed by the variable Nature destination landscape $(\mathrm{PCDL})(\beta 2=$ 0.218 ), followed by the variable Security order (ANTT) $(\beta 5=0.166)$, and the lowest impact is the variable Means of Transport $(\mathrm{PTVC})(\beta 3=0.121)$. Thus, hypotheses H2, H3, H4, H5, H7 are accepted at a 95\% confidence level. Finally, research results have shown that gender has an opposite effect on domestic tourist satisfaction $(\beta=-0,254$; and $\mathrm{P}$-value $=$ 0,000). In other words, female tourists tend to have a higher level of satisfaction than female tourists who travel in the South-West province of Vietnam. Gender refers to a set of characteristics that distinguish between men and women. In addition to physical or biological differences, men and women may have different characteristics, and their attitudes could influence consumer behavior (Hoyer and Maclnnis, 2010). Indeed, there are significant differences like observe the environment; process, evaluate and retrieve information regarding man and woman (Hoyer and Maclnnis, 2010). For example, women pay attention to both personal information and other information and they tend to assess in detail, in-depth messages, and make extensive decisions based on attributes. of the product. However, men focus only on personal information (and tend to use simple guesswork methods and process information based on certain details (Hoyer and Maclnnis, 2010).

Table 3. Summary table of regression analysis results of the model

\begin{tabular}{|l|c|c|c|c|}
\hline \multirow{2}{*}{ Variables } & \multicolumn{2}{|c|}{ Tourists' Satisfaction } & \multirow{2}{*}{ VIF } & Conclusion \\
\cline { 2 - 3 } & Beta coefficient & P-value & & Reject \\
\hline Tourism Infrastructure & 0.027 & 0.587 & 2.631 & Accept \\
\hline $\begin{array}{l}\text { Nature Destination } \\
\text { Landscape }\end{array}$ & 0.218 & 0.000 & 2.080 & Accept \\
\hline Transport & 0.121 & 0.001 & 1.347 & Accept \\
\hline $\begin{array}{l}\text { Food and Beverage \& } \\
\text { Shopping and } \\
\text { Entertainment Service }\end{array}$ & 0.314 & 0.000 & 1.816 & Accept \\
\hline Security \& Safety & 0.166 & 0.001 & 2.433 & Accept \\
\hline Tour Guide & 0.047 & 0.276 & 1.901 & Reject \\
\hline Perceived Price & 0.246 & 0.000 & 1.451 & Accept \\
\hline $\begin{array}{l}\text { Model explanation level } \\
\text { (adjusted R2) }\end{array}$ & \multicolumn{2}{|c|}{0.657} & \\
\hline & Control variables & \\
\hline Gender & -0.254 & 0.000 & 1.014 & Accept \\
\hline Age & -0.072 & 0.159 & 1.279 & Reject \\
\hline Income & -0.014 & 0.791 & 1.285 & Reject \\
\hline Education level & 0.007 & 0.880 & 1.097 & Reject \\
\hline
\end{tabular}

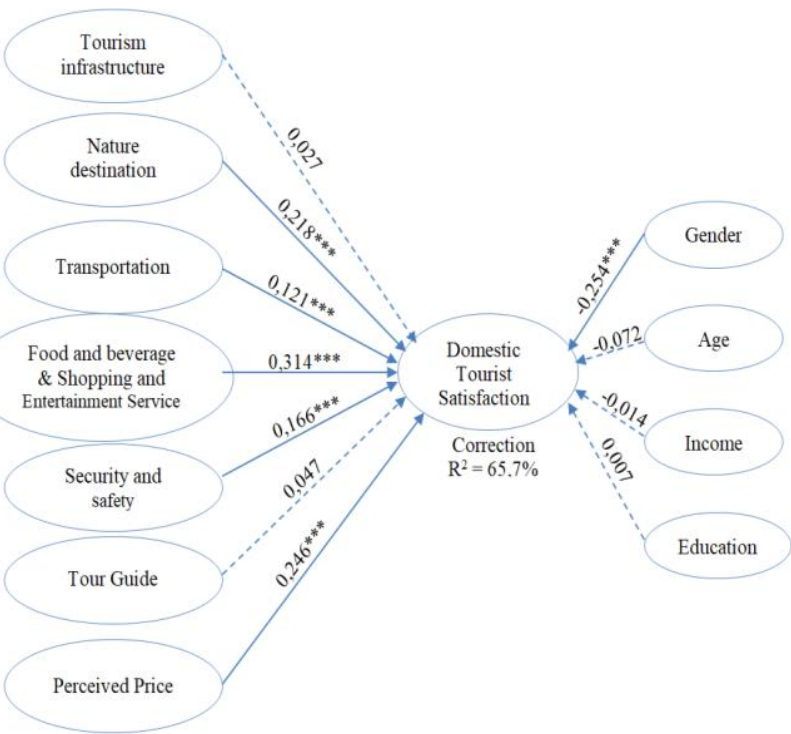

Figure 2. Model of the outcome of research (The model was drawn from data analysis)

Accordingly, it can be argued that women pay more attention to quality because they consider and evaluate in detail every aspect of the product and/or service they purchase whereas, male customers access aspects generally. Therefore, it is not surprising that a woman's product or service expectations are likely to be higher than that of male customers and their 
perception of the service is also lower than male customers, thus it affects the level of satisfaction. The results of this study indicated that the level of satisfaction of female tourists toward the service quality is higher than male tourists. The findings were in line with the researcher's expectations. Because women seem to emphasize quality aspects, they tend to collect further information and are more likely to evaluate after engaging in a detailed and comprehensive review of a message.

\section{CONCLUSION AND IMPLICATION}

\section{Conclusion}

Based on the general theory, a research model has been developed for this study. This model was tested with a sample of 457 domestic tourists to the South West of Vietnam. The research results show that there are a number of factors affecting domestic tourists' satisfaction with the quality of ecological services in Vietnam's Mekong Delta. With the results obtained, this study has positive contributions to management practices, as follows: (1) In terms of the scale used in this study, the results show that the entire scale used in the study is reliable (Cronbach's Alpha> 0.7) and could be used for other studies. (2) Pointed out factors affecting domestic tourists' satisfaction with the quality of ecotourism services in Vietnam's Mekong Delta. Specifically, the study has identified 5 factors affecting domestic tourist satisfaction, from strong to low, as follows: Food service, shopping, entertainment, perceived price, tourist landscape, security, order and safety, transportation. (3) Analyzed differences in satisfaction according to individual characteristics by independent sample T-test method, ANOVA showed that there was a difference in satisfaction by gender of visitors (Figure 2).

\section{Implication}

\section{Food and Beverage \& Shopping and Entertainment Service}

The research results show that "Food and beverage services, shopping and entertainment" are the factors which have the strongest influence on domestic tourists' satisfaction with the quality of ecotourism in the Mekong Delta, Vietnam. To increase the satisfaction of domestic tourists through this factor, the author proposes some governance implications as follows: The research findings show that the local goods are not rich and diverse, offering tourists too few choices for their shopping activities when traveling here. Therefore, the Department of Tourism in the Mekong Delta, Vietnam needs to have activities to create many unique products for the locality and regions such as U Minh Honey, Dat Mui Dried Prawn, Rach Goc Sesarmid Crabs. Besides, at tourist attractions, night markets should be organized to focus on specialties and deliver them to tourists. Besides, the results show that the number of shopping shops is too few and does not attract tourists.

To expand and develop shopping stores, it is necessary to have support from the state and relevant departments. Administrators need to call for investment, build shopping stores, supermarkets by cooperating with large domestic supermarket groups such as Co.op Mart, VinMart. In the Mekong Delta, Vietnam, there are many specialties such as grilled snakehead fish, grilled Anabas fish, fish sauce hot pot, goby porridge, a fried hamster with chili, hot pot, fried rice with tamarind, crab in the Vietnamese restaurants and eateries at tourist destinations should include these traditional dishes in the menu as well as diversify and process more dishes from specialties of each locality. The Department of Tourism of the Mekong Delta needs to build up a relationship with neighboring provinces such as Kien Giang, Bac Lieu, Soc Trang, Can Tho on tourism promotion to create conditions for travel business companies to cooperate with each other in organizing tours, improving the service quality. Travel agencies need to organize for tourists to participate in outstanding activities in the South West, Vietnam such as the Nghinh Ong festival, Tian Hou ceremony, Ky Yen festival, Than Nong ceremony, boat race. Also, the Department of Culture and Tourism should organize cultural activities on the weekends to promote distinctive folk songs and tales of the South. Besides, it is necessary to strongly develop the model of "miet vuon" (garden) tourism - During the day, guests and local residents go fishing, catch cramps, clams, crabs together to process and enjoy rustic dishes. At night, the family gathers to eat and drink, sing old folk songs, catch crabs and shrimps, and the model of "miet rung" (wilderness) - Getting honey with the local, taking pictures, picking wild vegetables processed into folk dishes such as grilled snakehead fish, stir-fried poems, young bee salad. At night, they would spend the night on a simple tray of rice, sip a few glasses of rice wine, humming some fairy tales, and listening to stories of Uncle Ba Phi. Finally, to ensure food is clean, it is necessary to have the attention of the Food Safety Department to food and beverage busines ses such as progressing to periodic checks, sudden checks on hygiene, and food safety. At the same time, granting certificates of eligibility for food hygiene and safety to businesses to help visitors feel secure when using their services.

\section{Perceived Price}

The research results show that "Perceived price" is the second-factor affecting domestic tourists' satisfaction with the quality of ecotourism in the Mekong Delta, Vietnam. In order to increase the satisfaction of domestic tourists through this factor, the author proposes some governance implications as follows: The results show that the entrance fees of tourist attractions are not reasonable. The Department of Culture and Tourism needs to control the entrance fee properly by posting the entrance fee for tourist attractions, avoid higher fares than regulations. Besides, research shows that the prices of goods and services do not commensurate with the quality received by tourists. Therefore, managers at tourist destinations need to control prices for goods and services by collecting customer opinions, reviews, and feedback to adjust prices so that they commensurate with the quality. The results showed that shopping prices did not match the expectations of visitors. Therefore, the managers of tourist attractions need to review the prices of products and goods sold in their resorts. At the same time, there is a need to have a customer care team to receive customer feedback, expectations, requests from tourists for the products they buy. Moreover, food and drink prices at tourist destinations are not suitable for tourists. Therefore, food and beverage prices must be clearly publicized on menus by individuals and organizations engaged in the food and beverage business. There are 
instructions for visitors to notify relevant local authorities when they are ripped off so as to quickly and thoroughly resolve the issue. In addition, it is essential to make bulletin boards in central locations where many tourists come, naming the restaurant or hotel that rip off their customers, or propagating and criticizing bad acts against tourists on social media. The local authorities which fail to solve this situation should be punished using appropriate measures.

\section{Nature destination Landscape}

The research results show that "Nature destination landscape" is the third-factor affecting domestic tourists' satisfaction with the quality of ecotourism in the Mekong Delta, Vietnam. In order to increase the satisfaction of domestic tourists through this factor, the author proposes some governance implications as follows: The results show that the artificial designs at the points are unable to impress tourists, thus failing to make them feel satisfied. Therefore, administrators at tourist sites need to call for investment in the construction of artificial works such as monuments, entertainment areas, artificial beaches, largescale eco-resorts to attract and meet the needs of tourists. Besides, tourists deem Mekong Delta's scenery not yet diverse. The landscape in the South West of Vietnam has not been fully exploited. Therefore, the authorities need to have a plan to exploit the unique characteristics of the mangrove area along with this special ecosystem. The administrator should have programs and activities on floating markets so that tourists can feel the fresh river atmosphere, enjoy songs and melodies.

\section{Security \& Safety}

The research results show that "Security and order" is the fourth-factor affecting domestic tourists' satisfaction with the quality of ecotourism in the Mekong Delta, Vietnam. It shows that domestic tourists are not satisfied with the security and safety in tourist destinations in the Mekong Delta, Vietnam. To increase the satisfaction of domestic tourists through this factor, the author proposes some governance implications as follows: The results show that there are no warning signs in dangerous areas for tourists, and tourist spots are not equipped to ensure safety for tourists. Therefore, administrators at tourist sites need to check and provide warning signs in dangerous areas that are likely to threaten the safety of visitors' lives and possessions such as providing protective equipment, including swimming buoys, helmets, gloves for visitors when participating in activities on waterways, roads. Also, at each tourist site, it is necessary to establish a rescue team in case of unexpected events. The results showed that the fact that tourists are dragged to shop and take photos at the attractions is still happening. This makes tourists feel uncomfortable. To address this problem, tourist sites should have security forces to observe and take preventive measures. The state needs to propagate to the people to have an awareness that tourism will give them a chance to improve their lives. From there, people will behave more friendly to tourists.

The state must strictly manage the population and create local rules. To ensure food safety and hygiene, the local food safety department should conduct regular inspections at tourist sites. Administrators need to check the food supply, ingredients, as well as processing process to ensure food safety for tourists. Moreover, at tourist sites, it is necessary to have a medical room to provide timely first aid in the event of a bad situation. In order for the sights to be safer, the administrators need to put in place a clear process for tourists to visit, to avoid crowding, pushing, and causing the lack of order, littering, and creating opportunities for thieves to sneak up on tourists' possessions. Finally, the state needs to support the police to patrol the tourist sites and impose sanctions on those violating the law.

\section{Transportation}

The research results reflect that "transportation" is the fifth-factor affecting domestic tourists' satisfaction with the quality of ecotourism in the Mekong Delta, Vietnam. To increase satisfaction through this factor, the author proposes some governance implications as follows: tourism organizations need to equip and invest in more comfortable and modern means of transport such as bed cars, which have televisions, wi-fi, toilets. The results show that the current means of transportation to tourist destinations is not diverse in terms of quantity and types. Therefore, tourist destinations need to cooperate with transport companies: car companies, boats, buses so that tourists have more choices of transportation to tourist attractions. Furthermore, in order to easily find information and buy tickets, there should be clear instructions on means of transport, prices, and schedules on the website of tourist destinations. Finally, tourist sites need to collect tourists' comments on modes of transport to improve transportation such as increasing river transport by boat, canoe to tourist destinations so that visitors can have an enjoyable experience.

\section{Gender}

This study shows that women's consumption expectations are higher and that they consider every aspect of the services they receive. Women's satisfaction is determined by their experience with the quality of services they receive, which is in contrast to that of men's. The findings in this study are also beneficial from the administrators' perspectives. The results showed that female tourists were more aware of service quality than male tourists. The number of female tourists is increasing, which is changing the market. Therefore, tourism marketers should review existing service strategies and introduce newer ones to suit the market.

\section{THE RESEARCH LIMITATION AND THE FUTURE RESEARCH}

Although the research has achieved the proposed research objectives, there are still some limitations as follows: First, the study was only conducted with research subjects who are domestic tourists. The results of the study are not highly representative. Therefore, the next study should survey domestic and foreign tourists for a better-rounded view. Secondly, this study only explains $65.74 \%$ of the variation of domestic tourists' satisfaction with the quality of eco-services in the 
Mekong Delta, Vietnam by the variation of 05 variables. As such, there are many other factors affecting satisfaction that the study has not found. Therefore, the next study needs further research to find out some new factors affecting the satisfaction of domestic tourists with the quality of ecological services in the Mekong Delta, Vietnam.

\title{
REFERENCES
}

Chinhphu (2020). Strategy on Viet Nam's tourism development until 2020, vision to 2030. [Accessed Jan 10 2021]. http://www.chinhphu. $\mathrm{vn} /$ portal/page/portal/English/strategies/strategiesdetails?categoryId=30\&articleId=10051267

Chuchu, T. (2020). The impact of airport experience on international tourists' revisit intention: A South African case. GeoJournal of Tourism and Geosites, 29(2), 414-427. https://doi.org/10.30892/gtg.29203-478

Cronin, J.J., \& Taylor, S.A. (1992). Measuring service quality: A reexamination and extension. Journal of Marketing, 56(3), 55-68. https://doi.org/10.2307/1252296

Foroni, I., Modica, P., \& Zenga, M. (2019). Residents' satisfaction with tourism and the european tourism indicator system in South Sardinia. Sustainability, 11(8), 22-43. https://doi.org/10.3390/su11082243

Giao, H.N.K., Hang, T.D., Son, L.T., Kiem, D., \& Vuong, B.N. (2020). Tourists' Satisfaction towards Bao Loc City, Vietnam. Journal of Asian Finance, Economics and Business, 7(7), 269-277. https://doi.org/10.13106/jafeb.2020.vol7.no7.269

Giao, H.N.K., Vuong, B.N., \& Tushar, H. (2020). The impact of social support on job-related behaviors through the mediating role of job stress and the moderating role of locus of control: Empirical evidence from the Vietnamese banking industry. Cogent Business \& Management, 7(1), 1-23. https://doi.org/10.1080/23311975.2020.1841359

Goliath-Ludic, K., \& Yekela, S. (2020). Resident's perception of the environmental impact of tourism: A case study of the bawa community in Butterworth, South Africa. GeoJournal of Tourism and Geosites, 33(4), 1527-1531. https://doi.org/10.30892/gtg.334spl12-603

Gronroos, C. (1990). Service management: A management focus for service competition. International Journal of Service Industry Management, 1(1), 6-14. https://doi.org/10.1108/09564239010139125

Hau, T.C., \& Omar, K. (2014). The impact of service quality on tourist satisfaction: The case study of Rantau. Mediterranean Journal of Social Sciences, 5, 1827-1832. https://doi.org/10.5901/mjss.2014.v5n23p1827

Hoyer, W.D., \& Maclnnis, D.J. (2010). Consumer Behavior (5th ed.). Cengage Learning, United States of America

Hunter, C., \& Green, H. (1995). Tourism and the Environment: A Sustainable Relationship? Routledge, New York.

Jiménez-García, M., Ruiz-Chico, J., \& Peña-Sánchez, A.R. (2020). Landscape and Tourism: Evolution of Research Topics. Land, 9(12), 117. https://doi.org/10.3390/land9120488

Kanwal, S., Rasheed, M.I., Pitafi, A.H., Pitafi, A., \& Ren, M. (2020). Road and transport infrastructure development and community support for tourism: The role of perceived benefits, and community satisfaction. Tourism Management, 77, 1-10. https://doi.org/10.1016/j.tourman.2019.104014

Kotler, P., \& Keller, K., L. (2012). Marketing Management. Prentice Hall, United States of America.

Kwok, S.Y., Jusoh, A., \& Khalifah, Z. (2016). The influence of service quality on satisfaction: Does gender really matter? Intangible Capital, 12(2), 444-461. http://dx.doi.org/10.3926/ic.673

Narayan, B., Ranjendran, C., \& Sai, L.P. (2008). Scales to measure and benchmark service quality in tourism industry: A second-order factor approach. Benchmarking: An International Journal, 15(4), 469-493. https://doi.org/10.1108/14635770810887258

Oliver, R.L. (2010). Satisfaction: A Behavioral Perspective on the Consumer (2nd Ed.). Routledge, New York.

Osman, Z., \& Sentosa, I. (2013). Mediating effect of customer satisfaction on service quality and customer loyalty relationship in Malaysian rural tourism. International Journal of Economics and Management Studies, 2(1), 25-37. http://ssrn.com/abstract=2196815

Parasuraman, A., Zeithaml, V.A., \& Berry, L.L. (1988). SERVQUAL: A multiple-item scale for measuring consumer perceptions of service quality. Journal of Retailing, 64(1), 12-40. https://psycnet.apa.org/record/1989-10632-001

Patwary, A.K., Omar, H., \& Tahir, S. (2021). The impact of perceived environmental responsibility ontourists' intention to visit green hotel: The mediating role of attitude. GeoJournal of Tourism and Geosite, 34(1), 9-13. https://doi.org/10.30892/gtg.34101-612

Pizam, A., Neumann, Y., \& Reichel, A. (1978). Dimentions of tourist satisfaction with a destination area. Annals of Tourism Research, 5(3), 314-322. https://doi.org/10.1016/0160-7383(78)90115-9

Setokoe, T.J. (2020). Community-based tourism: A panacea for community development in Nqileni Village, Eastern Cape, South Africa. GeoJournal of Tourism and Geosites, 34(1), 28-32. https://doi.org/10.30892/gtg.34104-615

Spreng, R.A., \& Mackoy, R.D. (1996). An empirical examination of a model of perceived service quality and satisfaction. Journal of Retailing, 72(2), 201-214. https://doi.org/10.1016/S0022-4359(96)90014-7

Stonehouse, B. (1999). Environmental Geology. Springer Netherlands, Dordrecht.

Vietnamplus (2019). Eco-tourism site to be developed in U Minh Ha National Park. [Accessed Jan 10 2021]. https://en.vietnamplus.vn/ ecotourism-site-to-be-developed-in-u-minh-ha-national-park/147219.vnp

Vuong, B.N., \& Giao, H.N.K. (2020). The impact of perceived brand globalness on consumers' purchase intention and the moderating role of consumer ethnocentrism: An evidence from Vietnam. Journal of International Consumer Marketing, 32(1), 47-68. https://doi.org/10.1080/08961530.2019.1619115

Vuong, B.N., Hieu, V.T., \& Trang, N.T.T. (2020). An empirical analysis of mobile banking adoption in Vietnam. Gestão e Sociedade, 14(1), 3365-3393 https://doi.org/10.21171/ges.v14i37.3078

Vuong, B.N., \& Suntrayuth, S. (2020). The impact of human resource management practices on employee engagement and moderating role of gender and marital status: An evidence from the Vietnamese banking industry. Management Science Letters, 10(7), 1633-1648. https://doi.org/10.5267/j.msl.2019.12.003

Wood, M. (2002). Ecotourism: Principles, Practices \& Policies for Sustainability, United Nations Environment Programme. United Nations Publication, France.

Zeithaml, V.A., \& Bitner, M.J. (2018). Services Marketing: Integrating Customer Focus Across The Firm. McGraw-Hill, Boston.

\author{
Article history: Received: 07.02.2021 Revised: 20.04.2021 Accepted: 15.06.2021 Available online: 30.06 .2021
}

